\title{
Genetic analysis of test days, 305 days and lifetime lactation records in Sahiwal cattle
}

\author{
Manjari Pandey ${ }^{1}$ and Raja $\mathrm{K} \mathrm{N}^{2}$
}

Received: 23 February 2020 / Accepted: 11 April 2020 / Published online: 12 July 2020

(C) Indian Dairy Association (India) 2020

\begin{abstract}
The present research was aimed to perform genetic analysis of first lactation monthly test day milk yields, first lactation 305 days and lifetime milk yield of Sahiwal cattle. Data were collected on 867 Sahiwal cows sired by 76 bulls over a period of 31 years. Complete genetic analysis of all the traits was done using Harvey (model 2). The heritability of MTDMY ranged from $0.12 \pm 0.06$ (TD10) to $0.48 \pm 0.09$ (TD4) by LSML. The heritability estimates for FL305DMY and LTMY were found to be $0.40 \pm 0.09$ and $0.34 \pm 0.07$ respectively. The estimates of phenotypic and genetic correlation among all the monthly test day milk yields ranged from 0.14 to 0.79 and 0.15 to 0.99 respectively. The genetic correlation of MTDMY and FL305DMY ranged from 0.66 (TD1) to 0.99 (TD7, TD10). The phenotypic correlation of MTDMY with FL305DMY ranged from $0.29 \pm 0.04$ (TD1) to $0.74 \pm 0.03$ (TD6). The knowledge of the heritabilities and correlations among the traits help in developing the prediction models for performance traits which assists in developing better, accurate and faster selection strategies for breeding programs.
\end{abstract}

Keywords: First lactation 305day milk yield, Genetic correlation, Heritability, Lifetime milk yield, Phenotypic correlation, Sahiwal cattle, Test day milk yield

'AGB Division, ICAR- National Dairy Research Institute, Karnal-

132001, Haryana, India

${ }^{2}$ AG\&B Division, ICAR- National Bureau of Animal Genetic Resources, Karnal- 132 001, Haryana

Manjari Pandey $(\bowtie)$

AGB Division, Indian Veterinary Research Institute, Izatnagar- 243

122, Bareilly, Uttar Pradesh India.

Email:mnpandey155@gmail.com

\section{Introduction}

India has a diverse and unique livestock population. As per $20^{\text {th }}$ livestock census, India has 192.49 million cattle out of which 142.11 million belong to indigenous/nondescript category. The recognized importance of indigenous cattle in traits like higher feed conversion efficiency, better adaptability to tropical conditions, resistance to heat and tropical diseases etc. has led to an increase in their population by $10 \%$ in 2019 as compared to previous census.

Sahiwal is one of the best indigenous dairy breed with highest milk production compared to other zebu breeds. Pure Sahiwal herds are available in Punjab, Rajasthan and some pockets of U.P. and Chhattisgarh. A fair understanding of genetic and phenotypic parameters of the population is needed for developing a suitable breeding strategy. The genetic makeup of a population is reflected in the parameters like heritability, genetic and phenotypic correlations between the performance traits. Test day (TD) model is a statistical procedure which considers genetic and environmental effect directly on the test day basis (Swalve, 1995). The usefulness of test day milk yield depends on genetic correlation between test day milk yield records and 305 days milk yield and also upon the accuracy with which sire evaluation can be obtained based on test day milk yield records. In the present investigation the heritabilities and correlation among the test day milk yields, first lactation 305 days milk yield and lifetime milk production are analyzed using Harvey.

\section{Materials and Methods}

\section{Data collection}

Data from history cum pedigree sheets and daily milk recording registers of Sahiwal cattle maintained at ICAR - National Dairy Research Institute (NDRI), Karnal, Haryana, were used for this study. The first, second, third, fourth, fifth and sixth lactation production records of Sahiwal over a period of 31years were recorded. Test day milk yield were recorded at monthly interval $\left(6^{\text {th }}, 35^{\text {th }}, 65^{\text {th }}, 95^{\text {th }}, 125^{\text {th }}, 155^{\text {th }}, 185^{\text {th }}, 215^{\text {th }}, 245^{\text {th }}, 275^{\text {th }}, 305^{\text {th }}\right.$ day of first lactation). 


\section{Statistical analysis}

The heritability of test day milk yields, were estimated using the genetic (co)variances, permanent environmental (co)variances and homogeneous residual variances of test day milk yield as per the procedures given by Jamrozik and Schaeffer (1997). For the estimation of heritability of test day milk yields one need to estimate-

\section{Estimation of heritability of test day milk yields}

The heritability of test day milk yield records at different DIM in first lactation was estimated as follows

$$
\begin{aligned}
& h(i)^{2}=\quad \sigma a(i)^{2} \\
& \sigma_{\mathrm{a}(i)^{2}}+\sigma_{p \mathrm{e}(i)^{2}}+\sigma_{\mathrm{e}(i)^{2}} \\
& h_{(i)^{2}}=\text { Heritability of test day milk yield on } i^{\text {h }} \text { DIM } \\
& \sigma_{a i i^{2}}^{2} \quad=\text { Genetic variance of test day milk yield on } \mathrm{i}^{\mathrm{h}} \text { DIM } \\
& \sigma_{p e c i^{2}}=\text { Permanent environmental variance of test day milt: yield on ith DIM and } \\
& \sigma_{(t-i)^{2}}=\text { Homogeneous residual variance of test day milk yield on } \mathrm{i}^{\text {ih }} \mathrm{DIM}
\end{aligned}
$$

\section{Estimation of genetic and phenotypic correlations}

\begin{tabular}{|c|c|c|c|c|}
\hline $\begin{array}{c}\text { Sources of variation } \\
\text { Between sires }\end{array}$ & $\begin{array}{c}\text { d.f. } \\
(S-1)\end{array}$ & $\begin{array}{c}S S \\
\Sigma,=X_{i} y_{5} / n-X . Y . N\end{array}$ & $\begin{array}{l}\text { MS } \\
\text { MSs }\end{array}$ & $\begin{array}{c}\text { EMS } \\
\sigma_{=2 x y+}^{2}+\mathrm{K} \sigma_{x}^{2} \text { xxy }\end{array}$ \\
\hline Within sires & $(\mathrm{N}-\mathrm{S})$ & $\Sigma \Sigma X_{i} Y_{i}-\Sigma, X_{i} Y_{i} n_{i}$ & MSe & $\sigma_{0}^{2}(x)$ \\
\hline Tota1 & $(N-1)$ & & & \\
\hline
\end{tabular}

The genetic and phenotypic correlations among different monthly test day milk yield, between test day milk yield and 305 days milk yield, between test day milk yield and life time milk yield were estimated from the analysis of variance /covariance using half sib data.

\section{Genetic correlation $\left(\mathbf{r}_{\mathrm{g}}\right)$}

The genetic correlation was calculated by using the following formula

$$
r_{g}(X Y)=\frac{\operatorname{Cov} S_{X Y}}{\sqrt{\left(\sigma_{x}^{2}\right)\left(\sigma_{y}^{2}\right)}}
$$

where,

Cov $\mathrm{S}_{\mathrm{XY}} \quad=$ Sire component of covariance between traits $\mathrm{X}$ and $\mathrm{Y}$

$\sigma_{\mathrm{x}}^{2}=$ Sire component of variance for trait $\mathrm{X}$

$\sigma_{\mathrm{y}}^{2}=$ Sire component of variance for trait $\mathrm{Y}$

The standard error of genetic correlation $\left(\mathrm{r}_{\mathrm{g}}\right.$ ) was estimated by using the following formula as given by Robertson (1959):

\section{S.E. $\left(r_{g}\right)=1-r_{g}^{2} \sqrt{\operatorname{SEE} \cdot\left(h^{2} x\right) S . E .\left(h^{2} y\right) /\left(h^{2} x\right)\left(h^{2} y\right)}$ $\sqrt{2}$}

$\left(\mathrm{h}_{\mathrm{x}}^{2}\right)$ and $\left(\mathrm{h}_{\mathrm{y}}^{2}\right)$ are the heritability estimates of the two traits $\mathrm{X}$ and $\mathrm{Y}$, respectively

\section{Phenotypic correlation $\left(r_{p}\right)$}

The phenotypic correlations were estimated as

$\left.\sigma_{\mathrm{e}}^{2}(\mathrm{Y})\right]$

$$
\left.\mathrm{r}_{\mathrm{p}(\mathrm{XY})}=\operatorname{Cov}_{\mathrm{s}(\mathrm{XY})}+\operatorname{Cov}_{\mathrm{e}(\mathrm{XY})} / \sqrt{\rrbracket} \sigma_{\mathrm{s}}^{2}(\mathrm{X})+\sigma_{\mathrm{e}}^{2}(\mathrm{X})\right]\left[\sigma_{\mathrm{s}}^{2}(\mathrm{Y})+\right.
$$

Where,

$\operatorname{Cov}_{s(\mathrm{XY})}=$ Sire component of covariance between traits $\mathrm{X}$ and $\mathrm{Y}$

$\mathrm{Cov}_{\mathrm{e}(\mathrm{XY})}=$ Error component of covariance between traits $\mathrm{X}$ and $\mathrm{Y}$

$\sigma_{\mathrm{S}}^{2}(\mathrm{X})=$ Sire component of variance for trait $\mathrm{X}$

$\sigma_{\mathrm{S}}^{2}(\mathrm{Y})=$ Sire component of variance for trait $\mathrm{Y}$

$\sigma_{\mathrm{e}}^{2}(\mathrm{X})=$ Error component of variance for trait $\mathrm{X}$

$\sigma_{\mathrm{e}}^{2}(\mathrm{Y})=$ Error component of variance for trait $\mathrm{Y}$

The standard error of the phenotypic correlations was calculated as (Panse and Sukhatme, 1967)

S.E. $\left(\mathrm{r}_{\mathrm{P}}\right) \sqrt{1-\mathrm{r}_{\mathrm{P}(\mathrm{XY})}^{2} / \mathrm{N}-2}$

Where,

$r_{p(X Y)}=$ Phenotypic correlation between the traits $X$ and $Y$

$\mathrm{N}-2$ = Degrees of freedom

The statistical significance of correlations was tested using ' $t$ ' test as given by Snedecor and Cochran (1967) at (N - 2) degrees of freedom.

\section{Results and Discussion}

Heritability estimates of monthly test day milk yields, first lactation 305 days milk yield and lifetime milk yield

The heritability of first lactation monthly test day milk yields ranged from $0.12 \pm 0.06$ (TD10) to $0.48 \pm 0.09$ (TD4) (Table 1). As the heritability of any trait is influenced by both genetic effects and the environmental effect so having variations in heritability of monthly test day milk records is quite obvious. The heritability is lower towards the later test days because of more environmental effect as compared to genetic effect. This information also points out that certain test day milk yields whose heritability is 
Table 1 Heritability estimates for monthly test-day milk yields, first lactation 305 days milk yield and life time milk yield in Sahiwal cattle

\begin{tabular}{llc}
\hline Milk yield traits & Test day & $\mathrm{h}^{2} \pm \mathrm{SE}$ \\
\hline TD1 & $6^{\text {th }}$ & $0.16 \pm 0.06$ \\
TD2 & $35^{\text {th }}$ & $0.30 \pm 0.07$ \\
TD3 & $65^{\text {th }}$ & $0.27 \pm 0.07$ \\
TD4 & $95^{\text {th }}$ & $0.48 \pm 0.09$ \\
TD5 & $125^{\text {th }}$ & $0.24 \pm 0.06$ \\
TD6 & $155^{\text {th }}$ & $0.29 \pm 0.07$ \\
TD7 & $185^{\text {th }}$ & $0.17 \pm 0.06$ \\
TD8 & $25^{\text {th }}$ & $0.15 \pm 0.06$ \\
TD9 & $245^{\text {th }}$ & $0.30 \pm 0.07$ \\
TD10 & $275^{\text {th }}$ & $0.12 \pm 0.06$ \\
TD11 & $305^{\text {th }}$ & $0.13 \pm 0.06$ \\
FL305DMY & & $0.40 \pm 0.09$ \\
LTMY & & $0.34 \pm 0.07$ \\
\hline
\end{tabular}

determined more by the genetic effects are much more useful and dependable for predicting the genetic superiority of a particular animal. In a study by Ratwan et al. (2020), heritability estimates for test day milk yields varied from 0.06 (TDMY8) to 0.40 (TDMY2). Gupta (2013) reported the heritability estimates of monthly test day yield ranging from $0.244 \pm 0.127$ to $0.463 \pm 0.172$. The heritability estimate for first lactation 305 days milk yield was $0.40 \pm 0.09$ and that of life time milk yield was $0.34 \pm 0.07$. Similar estimates for first lactation 305 days milk yield were reported by Gopal and Bhatnagar (1972), Singh (1981), Gandhi and Gurnani (1995), Mohanty (2001), Debbarma et al.(2010). Higher estimates were reported by Tomar et al. (1996), Dongre (2013) and Gupta (2013) The heritability estimates were reported to be low for first ( 0.072 to 0.079 ) lactation 305 -day milk yield by Ved Prakash et al. (2017).

\section{Genetic and phenotypic correlations among monthly test day milk yields and 305 days milk yield, lifetime milk yield}

The estimates of genetic and phenotypic correlations among first lactation monthly test day milk yields with first lactation 305 days and lifetime milk yield are presented in Table 2. The genetic correlations among first lactation monthly test day milk yields and first lactation 305 days milk yield were found to be positive and highly significant $(\mathrm{p}<0.01)$. TD2 to TD5 and TD7 to TD10 showed the highest genetic correlation with first lactation 305 days milk yield which suggests that these first lactation test days can predict the FL305DMY to a better extent and thus can be used for its prediction. Higher the correlation among the independent and dependent variable, higher is the accuracy of the prediction model.

The phenotypic correlation of monthly test day milk yields with FL305DMY ranged from $0.29 \pm 0.04$ (TD1) to $0.74 \pm 0.03$ (TD6). Gupta (2013) reported the genetic and phenotypic correlation between the test day milk yields and first lactation 305 days milk

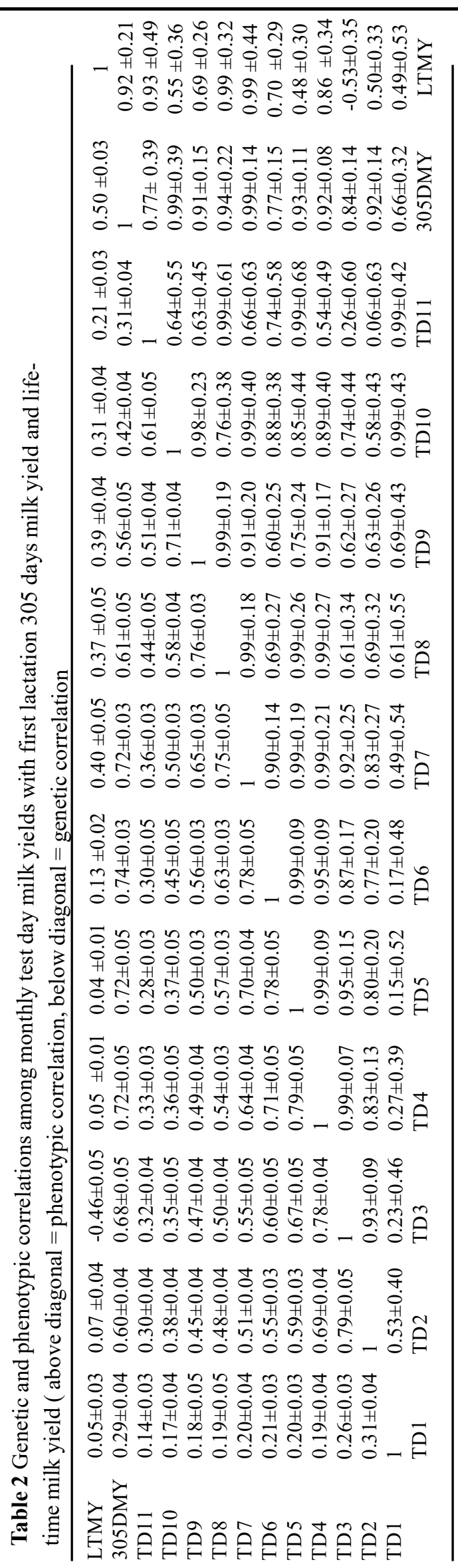


yield as -0.12 to 0.99 and 0.21 to 0.84 and Ved Prakash (2017) reported the range as -0.17 to 0.99 and 0.22 to 0.83 respectively in Sahiwal.

\section{Conclusions}

The genetic and phenotypic parameters of monthly test day milk yield, first lactation 305 days and life time milk yield were estimated using LSML software. The heritability of above mentioned traits were estimated using paternal half-sib correlation method. From the above study it can be concluded that the heritability of first lactation monthly test day milk yields ranged from low to medium with highest heritability at fourth test day i.e. on $95^{\text {th }}$ day. First lactation 305 days milk yield was found to be highly heritable and life time milk yield showed medium heritability. The estimates of phenotypic and genetic correlation among all the first lactation monthly test day milk yields ranged from 0.14 to 0.79 and 0.15 to 0.99 respectively. First test day milk yield had the lowest and sixth test day milk yield had the highest phenotypic correlation with FL305DMY. The genetic correlation of seventh and tenth first lactation monthly test day milk yields with first lactation 305 days milk yield was found to be the highest in the present study. TD2 to TD5 and TD7 to TD10 milk records showed higher genetic correlation with first lactation 305 days milk yield. This suggests that better statistical models with higher accuracy can be developed for the prediction of first lactation 305 days and lifetime milk yield of Sahiwal cattle using test day milk records having higher genetic correlation with them. This will also reduce the labor and expenditure of maintaining records by the farmers and help in developing better strategies of selection in cattle breeding programs.

\section{References}

Debbarma M, Gandhi RS, Raja TV, Singh A, Sachdeva GK (2010) Influence of certain non-genetic factors on test day milk records in Sahiwal cattle. Indian J Dairy Sci 63: 504-506

Dongre VB, Gandhi RS, Singh A, Sachdeva GK, Singh RK, Gupta A (2013) Influence of non-genetic factors on fortnightly test day milk yields and first lactation 305-day milk yield in sahiwal cattle. Indian J Ani Res. 47: 181-183

Gandhi RS, Gurnani, M (1995) Lactation-wise heritabilities of some economic traits in Sahiwal cattle. Indian J Dairy Sci 48: 75-77

Gopal D, Bhatnagar DS (1972) The effect of age at first calving and first lactation yield on lifetime production in Sahiwal cattle. Indian $\mathrm{J}$ Dairy Sci 25: 129-133

Gupta AK (2013) Genetic evaluation of Sahiwal cattle using lactation curve models. Ph.D. Thesis, NDRI (Deemed University), Karnal, Haryana, India.

Jamrozik J, Schaeffer LR (1997) Estimates of genetic parameters for a test day model with random regressions for yield traits of first lactation Holsteins. J Dairy Sci 80: 762-770

Mohanty JS (2001) Principal component analysis: A multi trait selection criterion in Sahiwal cattle. M.Sc. Thesis, NDRI, (Deemed University), Karnal, India

Panse VG, Sukhatme PV (1967) Statistical methods for agricultural workers ICAR, New Delhi

Ratwan P, Chakravarty AK, Kumar M, Sharma N, Joshi P (2020) Genetic analysis of first lactation test day traits in Sahiwal cattle. Indian J Anim Sci 90: 99-101

Singh SK (1981) Herd size and its influence on genetic change for economic traits in Sahiwal. Ph.D. Thesis, Kurukshetra University, Kurukshetra, India

Snedecor GW, Cochran WG (1967) Statistical methods. Oxford \& IBH Publ. Co., New Delhi, India

Swalve HH (1995) The effect of test day models on the estimation of genetic parameters and breeding values for dairy yield traits. J Dairy Sci 78: 929-938

Tomar AK, Prasad RB, Bhadula SK (1996) First lactation performance of Holstein, Sahiwal and their half-breds in Tarai region of Northern India. Indian J Anim Res 30: 129-133

Ved Prakash, Gupta AK, Singh M, Ambhore GS, Singh A, Gandhi RS (2017) Random regression test-day milk yield models as a suitable alternative to the traditional 305-day lactation model for genetic evaluation of Sahiwal cattle. Indian J Anim Sci 87: 340-344 